\title{
O ENSINO DE HISTÓRIA REGIONAL NO LIVRO DIDÁTICO DE MATO GROSSO DO SUL (2005)
}

\author{
THE TEACHING OF REGIONAL HISTORY \\ IN THE MATO GROSSO DO SUL'S TEXTBOOK (2005)
}

Vivianny Bessão de Assis $^{1}$

Dennis Rodrigo Damasceno Fernandes ${ }^{2}$

\begin{abstract}
RESUMO: Com os objetivos de contribuir para a história regional do Mato Grosso do Sul apresentam-se, neste texto, resultados finais da análise da configuração textual do livro didático, intitulado História do Mato Grosso do Sul (2005), elaborado para o $5^{\circ}$ ano do Ensino Fundamental. Por meio de processos de localização, seleção, reunião e ordenação de fontes documentais presentes nos acervos escolares de escolas estaduais do interior de Mato Grosso do Sul, deparamo-nos com - livro aqui analisado. Os resultados da pesquisa demonstram que se trata do livro com maior circulação nas escolas sobre história regional, publicado em duas edições (2005; 2008), e novamente aprovado e recomendado pelo Programa Nacional do Livro Didático - PNLD 2013. Ele propõe uma perspectiva de ensino em história linear, contém 15 capítulos dos quais 12 apresentam uma discussão mais detida sobre a história regional, enquanto os demais se inserem no contexto da história do Brasil. As opções teórico-metodológicas estabelecidas para o desenvolvimento desta pesquisa ancoram-se na abordagem histórica, com base nas contribuições da História Cultural. Por meio da análise tem sido possível compreender, que se trata de um texto adequado, mas com muitos silenciamentos em relação aos habitantes do pantanal, das fronteiras, do centro do estado e das demais etnias existentes na região. O livro também não oferece uma problematização de fontes que conduzam os discentes a uma reflexão de seu papel histórico na sociedade em que vivem.
\end{abstract}

Palavras-chaves: Ensino de história. Livro didático. Mato Grosso do Sul.

\footnotetext{
${ }^{1}$ Professora Adjunta do curso de Pedagogia da Universidade Federal de Mato Grosso do Sul, campus de Naviraí-MS. Membro integrante do GPHELLB - Grupo de Pesquisa "História do ensino de língua e literatura no Brasil".

2 Mestrando em "História Social" pelo Programa de Pós-Graduação em História pela Universidade Estadual de Londrina-PR. Professor de História da Educação Básica no Estado de Mato Grosso do Sul.
} 


\begin{abstract}
With the objectives of contributing to the regional history of Mato Grosso do Sul, we present, in this text, final results of the textual configuration analysis of the textbook, entitled History of Mato Grosso do Sul (2005), prepared for the 5th year of Elementary School. Through the processes of location, selection, meeting and ordering of documentary sources present in the school collections of state schools in the interior of Mato Grosso do Sul, we have come across the book analyzed here. The results of the research show, to date, that it is the only book produced in this state on regional history. It proposes a perspective of teaching in linear history, it contains 15 chapters of which 12 present a more detailed discussion about regional history, while the others are inserted in the context of the history of Brazil. The theoretical-methodological options established for the development of this research are anchored in the historical approach, based on the contributions of Cultural History. Through the analysis, it has been possible to understand that this is an adequate text, but with a lot of silencing in relation to the inhabitants of the wetlands, the borders, the center of the state and other ethnic groups in the region. The book also does not offer a problematization of sources that lead the students to a reflection of their historical role in the society in which they live.
\end{abstract}

Key-words: History teaching. Textbook. Mato Grosso do Sul.

\title{
Introdução
}

Com os objetivos de compreender a história do ensino de história no Mato Grosso do Sul apresentam-se, neste texto, resultados da análise da configuração textual do livro didático, intitulado História do Mato Grosso do Sul (2005), elaborado para o $5^{\circ}$ ano do Ensino Fundamental. Este estudo é decorrente do projeto de pesquisa "Acervos escolares e fontes para a história da educação de Naviraí-MS", ainda em andamento, que tem como objetivos organizar os acervos escolares das escolas estaduais de Naviraí, interior de Mato Grosso do Sul, por meio de processos de localização, seleção, reunião e ordenação de fontes documentais visando à elaboração de um "instrumento de pesquisa" ou "guia de fontes" que contribua para a produção de fontes sobre a história da educação sul-mato-grossense. 
O processo de localização e ordenação das fontes documentais levounos até o livro didático aqui analisado ${ }^{3}$. As opções teórico-metodológicas estabelecidas para o desenvolvimento desta pesquisa ancoram-se na abordagem histórica, com base nas contribuições da História Cultural, pautando-nos, especialmente, em Chartier (1990, 2011) e Le Goff (2003). Utilizamos também Mortatti (1999, 2000); Bittencort (2009) e Martins (2011). Além da pesquisa bibliográfica, foi realizada uma entrevista semiestruturada com uma professora que leciona no $5^{\circ}$ ano do Ensino Fundamental, na rede pública de ensino de Naviraí, que em 2017 estava utilizando o livro didático em suas aulas.

Quanto à pesquisa histórica, a entendemos como propõe Mortatti (1999),

[...] um tipo de pesquisa científica, cuja especificidade consiste, do ponto de vista teórico-metodológico, na abordagem histórica - no tempo - do fenômeno educativo em suas diferentes facetas. Para tanto, demanda a recuperação, reunião, seleção e análise de fontes documentais, como mediadoras na produção do objeto de investigação. (MORTATTI, 1999, p. 73).

O trabalho historiográfico do pesquisador descrito acima "[...] situase na confluência entre o tempo do objeto investigado e o tempo do sujeito investigador [...]" (BOTO, 1994, p. 24). Por isso é importante a materialidade do documento na pesquisa histórica. De acordo com esse ponto de vista, utilizamos o termo documento, neste texto, como o definiu Le Goff (2003).

O documento não é inócuo. É, antes de mais nada, o resultado de uma montagem, consciente ou inconsciente, da história, da época, da sociedade que o produziram, mas também das épocas sucessivas durante as quais continuou a viver, talvez esquecido, durante as quais continuou a ser manipulado, ainda que pelo silêncio. O documento é uma coisa que fica, que dura, e o testemunho, o ensinamento (para evocar a etimologia) que ele traz devem ser primeiro lugar analisados, desmistificando- Ihes o seu significado

\footnotetext{
${ }^{3}$ Por meio da pesquisa documental localizamos a publicação de um outro livro didático sobre a história de Mato Grosso do Sul, trata-se de: VALDEZ, Diane; AMARAL, Miriam Bianca do. História de Mato Grosso do Sul, 40. ou 50. ano. Curitiba, PR: Base Editora, 2011. No entanto, ele não será analisado neste texto, pois não foi possível localizar o exemplar físico desse livro nas escolas pesquisadas. Em contrapartida, o livro aqui analisado é amplamente utilizado em turmas do Ensino Fundamental I, II e no Ensino Médio.
} 
aparente. O documento é monumento. Resulta do esforço das sociedades históricas para impor ao futuro - voluntário ou involuntariamente - determinada imagem de si próprias. No limite, não existe um documento-verdade. Todo documento é mentira. Cabe ao historiador não fazer o papel de ingênuo. (LE GOFF, 2003, p. 535-538).

Também para Chartier (1990), a relação entre o pesquisador e os documentos escolhidos como fonte da pesquisa é complexa, pois exige um esforço do pesquisador em não vê-los como "a verdade", mas como representações sociais elaboradas por sujeitos de uma época determinada. Assim, a vertente da História Cultural que utilizamos, com base em Chartier (1990), é aquela que "[...] tem por principal objecto identificar o modo como em diferentes lugares e momentos uma determinada realidade social é construída, pensada, dada a ler". (CHARTIER, 1990, p. 16-17).

É também necessário considerar "[...] os grupos que as forjam [...]" neste caso, o livro didático aqui analisado, pois "[...] não são de forma alguma discursos neutros: produzem estratégias e práticas (sociais, escolares, políticas) que tendem a impor uma autoridade à custa de outros [...]". (CHARTIER, 1990, p. 17).

De acordo com Bittencort (2009), o livro didático é um objeto de "múltiplas facetas", e para sua elaboração e uso existem muitas interferências, caracteriza-se, nessa dimensão material, por ser uma mercadoria, ligada ao mundo editorial e à lógica da indústria cultural do sistema capitalista, veículo de um sistema de valores, de ideologias, de uma cultura de determinada época e de determinada sociedade. (BITTENCORT, 2009).

Trata-se de um objeto cultural de difícil definição por ser uma obra bastante complexa, que se caracteriza pela interferência de vários sujeitos em sua produção, circulação e consumo. Possui ou pode assumir funções diferentes dependendo das condições, do lugar e do momento em que é produzido e utilizado nas diferentes situações escolares. (BITTENCORT, 2009, p. 301).

Cônscios desses aspectos, esta pesquisa teve como objetivos compreender a história regional de Mato Grosso do Sul abordada no livro 
didático História do Mato Grosso do Sul (2005) e compreender como o ensino sobre essa história é proposto neste livro. Para isso, adotamos procedimentos da pesquisa histórica, realizada por procedimentos documentais e bibliográficos, e optamos pela análise da "configuração textual" que, segundo Mortatti (2000, p.31) consiste em enfocar:

[...] o conjunto de aspectos constitutivos de determinado texto, os quais se referem: às opções temáticoconteudísticas (o quê?) e estruturais formais (como?), projetadas por um determinado sujeito (quem?), que se apresenta como autor de um discurso produzido de determinado ponto de vista e lugar social (de onde?) e momento histórico (quando?), movido por certas necessidades (por quê?) e propósitos (para quê), visando a determinado efeito em determinado tipo de leitor (para quem?) e logrando determinado tipo de circulação, utilização e repercussão.

A análise proposta baseia-se no conjunto de aspectos que, interrelacionados, constituem o sentido de um texto. Esse conjunto "[...] propicia ao investigador: reconhecer e interrogar determinado texto como configuração textual 'saturada de agoras' [...] e dele produzir uma leitura possível e autorizada, a partir de seus objetivos, necessidades e interesses". (MORTATTI, 2000, p. 31).

De acordo com Mortatti (2001), o método de análise da "configuração textual" possibilita explicar uma "[...] representação, a partir da problematização de outras representações construídas e tomadas como corpus [...]" (p.184), mas essas representações não são em si "objetos de investigação", porque decorrem de um ato interpretativo do pesquisador. "Os sentidos e as explicações podem ser 'encontradas' dentro da configuração textual, ponto de partida e chegada do trabalho investigativo." (MORTATTI, 2001, p. 184).

Assim, a análise buscou compreender os diferentes aspectos constitutivos do sentido do livro, na certeza de que o "sentido" não reside apenas no seu conteúdo. Os aspectos observados foram: a formação e atuação profissional dos autores, instituições responsáveis por sua publicação e circulação; forma e conteúdo neles expressos; o público a 
quem se destinava; os objetivos e necessidades a que respondia; o momento histórico e lugar social em que esse livro foi produzido.

Assim, este texto está organizado da seguinte forma: uma introdução na qual situamos os objetivos da pesquisa e as opções teóricometodológicas deste estudo, em seguida, apresentamos o livro didático, seus autores, a editora em que foi publicado e número de edições localizadas, o conteúdo nele abordado e, por fim, as considerações finais sobre a análise. Segue-se, portanto, aspectos da apresentação do livro didático.

\section{Apresentação do livro didático}

\subsection{Autores do livro didático}

O livro didático foi produzido em coautoria por três professoras atuantes no estado de Mato Grosso do Sul, são elas: Lori Alice Gressler, Luiza Mello Vasconcelos e Zélia Peres de Souza. A primeira autora possui quase 45 anos dedicados ao ensino e a preservação da memória da cidade de Dourados e de Mato Grosso do Sul. É Doutora em Educação pela Mississippi State University (EUA), Mestre em Educação pela Organização dos Estados Americanos (OEA/UFSM) e Licenciada em Pedagogia pela Universidade Federal de Santa Maria (RS).

Foi professora da Universidade Federal de Santa Maria (RS) e da Universidade Federal de Mato Grosso do Sul (UFMS). Lori Gressler foi ainda vereadora por Dourados e vice-prefeita dessa mesma cidade. Algumas das produções escritas da autora são: Aspectos históricos do povoamento e da colonização do Estado de Mato Grosso do Sul (1988); O estado de Mato Grosso do Sul (1979); Dourados 60 anos de emancipação 1935-1995 (1995); Memória de Dourados: ruas, edifícios e logradouros públicos (1996).

Luiza Mello Vasconcelos possui graduação em Letras pela Universidade Estadual de Mato Grosso (MT), especialização em Língua Inglesa pela Universidade do Texas e mestrado em Letras pela Pontifícia Universidade Católica do Paraná (PUC-PR). Atualmente é Chefe da Divisão 
de Publicações da Universidade Estadual de Mato Grosso do Sul (UEMS). Tem experiência na área de Linguística, com ênfase em Ensino de Línguas, atuando principalmente nos seguintes temas: Mato Grosso do Sul, literatura brasileira, linguística aplicada e processo de escrita. Publicou dois livros sobre Mato Grosso do Sul em coautoria com Louri Gressler: Mato Grosso do Sul: Aspectos históricos e geográficos (2005) e História e Geografia de Mato Grosso do Sul (2005). Esses livros tiveram o mesmo ano de publicação do livro didático aqui analisado e também foram publicados pela mesma editora: FTD (SP).

Zélia Peres de Souza possui graduação em História pela Fundação Universidade Federal de Mato Grosso do Sul (UFMS) e mestrado em Desenvolvimento Sustentável pelo Centro de Desenvolvimento Sustentável (UnB/DF). Tem mestrado multidisciplinar com ênfase em Antropologia, Política e Gestão Ambiental, com trabalhos realizados nas Comunidades Indígenas das etnias Kaiowá, Guarani e Terena, atuando principalmente nos seguintes temas: cidadania, economia, natureza, educação e dignidade da pessoa humana. Em seu currículo lattes localizamos dois livros publicados também 2005 com as autoras apresentadas anteriormente, são eles: Mato Grosso do Sul: História (2005) e Mato Grosso do Sul: Geografia e História (2005). Esses livros apresentam títulos com poucas diferenças entre eles, o que nos chama a atenção é que foram publicados no mesmo ano e pela mesma editora. Até o momento, não foi possível discernir com certeza se se tratavam de publicações diferentes ou se receberam uma nova capa e novo título quanto adotados pelo Ministério da educação como parte do Programa Nacional do Livro Didático (FNDE). A seguir apresentamos aspectos editoriais do livro analisado.

\section{Livro didático: editora e edições}

O livro didático é um tipo de livro produzido para fins educativos, visando principalmente o público escolar. De acordo com Eloisa de Mattos Höfling (2000), o livro didático e a escola mantêm uma relação íntima desde a década de 1930, quando em 1938, pelo Decreto-Lei n. 1006, 
instituiu-se no Brasil a Comissão Nacional do Livro Didático, que ficou responsável por sua produção e utilização nas escolas. (HÖFLING, 2000).

Atualmente, a relação entre Governo e o mercado dos livros didáticos é mediada pelo Programa Nacional do Livro Didático (PNLD), criado em 1985, quando o MEC passou a ser o consumidor oficial desses produtos. Conforme Höfling (2000), desse período em diante é possível observar a relação entre o governo e o setor privado - nesse caso, as editoras - e perceber ainda que há um número bem reduzido de editoras que frequentemente têm conseguido a aquisição dos livros pelo MEC.

Com base nos dados disponibilizados pela antiga Fundação de Assistência ao Estudante (FAE), extinta em 1996, Höfling (2000) apresenta uma tabela com a participação das editoras que vem conseguindo as aquisições pelo MEC PNLD (1985-1991), são elas: Ática, Brasil, Idep, FTD, Nacional, Saraiva e Scipione.

O livro didático analisado foi publicado pela editora FTD, fato que confirma essa editora como "parceira" do MEC, evidenciando o recorrente monopólio do mercado editorial em relação aos livros didáticos ao longo do tempo no país. O Parque Gráfico da FTD atualmente está localizado na cidade de Guarulhos (SP) e foi inaugurada em 1988, é um dos mais bem equipados parques gráficos do segmento de livros didáticos, com 60 mil metros quadrados de área total e 51 mil metros quadrados de área construída. (FDT, 2018). A história dessa editora começou em 1883 e teve esse nome em homenagem ao Supervisor Geral do Instituto Marista Frère Théophane Durand que atuou na instituição de 1883 a 1907 . Em sua gestão, incentivou a produção de livros escolares que passaram a integrar a coleção que recebeu o título de Coleção de Livros Didáticos FTD. Muitos desses livros foram adotados tanto por escolas Maristas como por outras redes de escolas particulares e públicas na França e nos países onde os Maristas passaram a trabalhar.

Em 1897, Frère Théophane Durand determinou a vinda dos primeiros Irmãos Maristas para o Brasil, e com eles vieram também os livros da FTD, que já faziam parte da rotina dos colégios Maristas em diversos países. 
Logo surgiram traduções e adaptações de várias dessas obras, bem como novos livros passaram a ser escritos.

Em 1902, os Maristas publicaram o primeiro livro FTD no Brasil: Exercícios de Cálculo sobre as Quatro Operações, acompanhado de problemas, traduzido e adaptado pelo Irmão Andrônico, que foi diretor de colégios Maristas no Brasil (FTD, 2018). Essa editora tem em sua história uma ligação recorrente com o mercado livreiro educacional no Brasil, tornando-se no século XX uma das maiores editoras especializadas em livros didáticos, dedicando-se a cobrir todas as áreas de ensino.

Munakata (2012) explica que em 1996, o MEC instituiu uma comissão de avaliação prévia dos livros didáticos com a missão de avaliá-los e emitir pareceres com base nos quais se basearia para adquirir esses livros. Desde então, é dessa forma que a avaliação vem ocorrendo. No entanto, Munakata (2012) aponta que esses avaliadores são, em sua maioria, professores universitários que "[...] recrutados da universidade [...] nem sempre estão habituados às práticas de sala de aula [...]" (MUNAKATA, 2012, p. 62), fato que gera problemas em relação à inadequação do livro com o desenvolvimento da língua escrita dos alunos.

De acordo com Bittencort (2009) o livro didático também é um

[...] suporte de conhecimentos escolares propostos pelos currículos educacionais. Essa característica faz que o Estado esteja sempre presente na existência do livro didático: interfere indiretamente na elaboração dos conteúdos escolares veiculados por ele e posteriormente estabelece critérios para avaliá-lo, segundo, na maior parte das vezes, os pressupostos dos currículos escolares institucionais. (BITTENCORT, 2009, p. 301, grifos da autora).

Nesse sentido, a "mão" do estado está sempre presente na elaboração dos conteúdos dos livros didáticos, por meio do currículo prescrito, seguidos pelas editoras.

O livro didático História do Mato Grosso do Sul foi publicado em $1^{\text {a. }}$. edição no ano de 2005 e aprovado para compor o Programa Nacional do Livro Didático (PNLD) nos anos de 2007, 2008 e 2009, utilizado na então chamada $4^{a}$. série do Ensino Fundamental, conforme observa-se na capa do livro abaixo. 
Figura 1 - Capa do livro didático História do Mato Grosso do Sul, de 2005

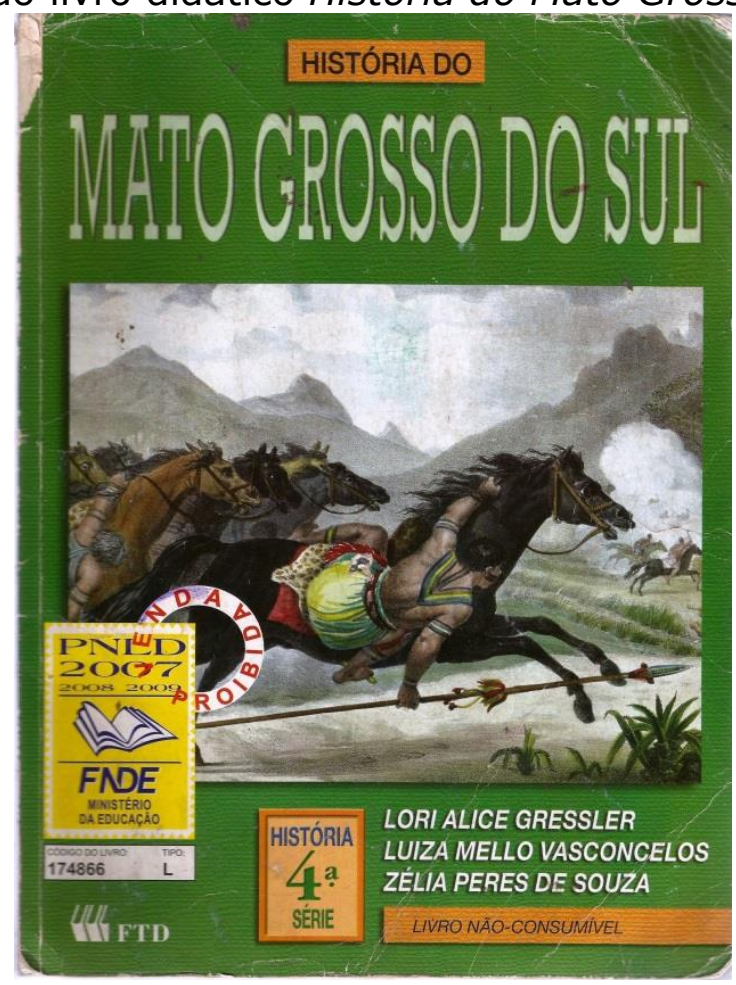

Fonte: Acervo da escola Juracy Alves Cardoso (MS).

Na capa do livro consta uma pintura de Debret que mostra indígenas do povo Guaicuru que são conhecidos como "índios cavaleiros". Essa imagem também aparece de forma ilustrativa no capitulo 2 "Os primeiros ocupantes da terra".

O livro teve uma nova reimpressão em 2008, sendo novamente aprovado para o próximo triênio: 2010, 2011 e 2012.

Figura 2 - Capa do livro didático História do Mato Grosso do Sul, de 2008 


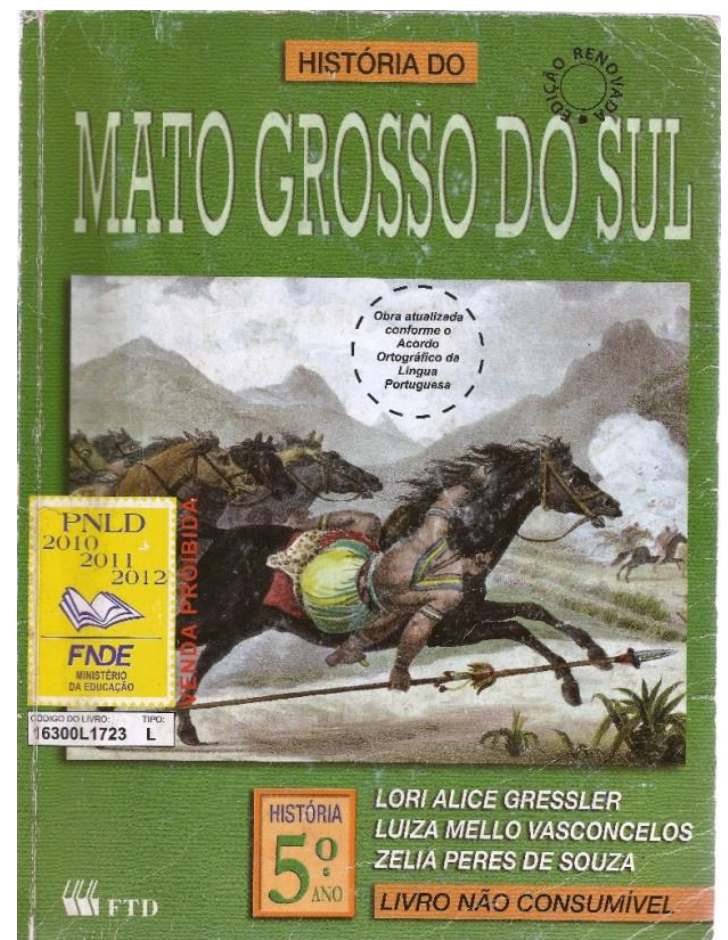

Fonte: Acervo da escola Juracy Alves Cardoso (MS)

Houve poucas atualizações nessa edição que visou atender ao novo Acordo Ortográfico de Língua de Portuguesa e algumas alterações na capa em relação à denominação da turma para qual o livro foi publicado, conforme projeto de lei $n^{\circ}$ 144/2005 que estabelece a duração mínima de nove anos para o Ensino Fundamental ${ }^{4}$ que passou a denominar as etapas de escolarização em anos e não mais em séries. Os conteúdos e a ordem de apresentação mantiveram-se as mesmas.

\section{Estrutura do livro didático}

O livro contém uma breve apresentação, na qual as autoras explicam que tratarão apenas do estado de Mato Grosso Sul, embora muitas vezes

\footnotetext{
${ }^{4}$ Em janeiro de 2006, o Senado Federal aprovou o Projeto de lei $n^{\circ} 144 / 2005$ que estabelece a duração mínima de nove anos para o Ensino Fundamental. Essa mudança acabou por acrescentar um ano a mais na formação dessa etapa do ensino brasileiro. Na mesma ocasião, também foi aprovada a matrícula obrigatória a partir dos seis anos de idade. De acordo com o texto da lei, até o ano de 2010, todas as escolas do território nacional deveriam seguir as novas determinações do ensino, agora denominado em "anos" e não mais em "séries". Disponível em: <http://portal.mec.gov.br/ensino-fundamental-de-noveanos >. Acesso em: 29 set. 2018.
} 
façam referência a antiga região de Mato Grosso. O livro apresenta uma linguagem clara, no entanto acadêmica e repleta de conceitos, conforme é possível observar por meio do fragmento:

\begin{abstract}
A história preocupa-se com o estudo das transformações vivenciadas por um grupo social. Ela é, portanto, dinâmica. Ao longo do tempo, o ser humano foi mudando sua forma de pensar e agir. Até o significado das palavras está sujeito a modificações. [...] Não podemos modificar o passado. É o conhecimento deste passado que muda. Mudam, portanto, as interpretações e a compreensão dos fatos. (GRESSLER; VASCONCELOS; KRUGER, 2008, p. 9).
\end{abstract}

$\mathrm{Na}$ apresentação do livro didático História do Mato Grosso do Sul (2005), as autoras expõem os objetivos do livro direcionando para a necessidade do estudo da História Regional: "[...] o que queremos é que você (discente) conheça mais sobre a história do nosso estado e continue a construí-la." (p. 3).

O livro é composto por 160 páginas e organizado em 15 capítulos, com os seguintes títulos: 1. "O estudo da História", 2. "Os primeiros ocupantes da terra", 3. "O sonho das descobertas", 4. "A colonização da América", 5. "A ocupação de Mato Grosso do Sul: o domínio espanhol", 6. "A ocupação de Mato Grosso do Sul: o domínio de Portugal", 7. "Origem e evolução dos municípios de Mato Grosso do Sul: séculos XIX e XX", 8. "A Guerra do Paraguai e Mato Grosso do Sul", 9. "Os movimentos pela emancipação do sul do estado de Mato Grosso", 10. "A história do cultivo da erva-mate em Mato Grosso do Sul", 11. "O desenvolvimento da pecuária em Mato Grosso do Sul", 12. "A agricultura e a indústria em Mato Grosso do Sul", 13. "Transportes e comunicações em Mato Grosso do Sul", 14. "Nossa gente, nosso cultura", 15. "Memórias da educação em Mato Grosso de Sul".

Dos 15 capítulos, 12 fazem referência direta a História do Mato Grosso do Sul. Os capítulos são iniciados com uma ilustração que faz referência ao conteúdo. Chartier (1990) aponta aspectos relevantes em relação a História da Leitura indicando que existem etapas que envolvem a leitura como a produção, circulação e apropriação dos materiais escritos. Desta maneira, então, as ilustrações iniciais dos capítulos apresentam um suporte de materialidade do texto que condiciona a leitura do discente para 
um referencial específico de índio idílico, em ambiente que representa um tipo de jardim do Éden, constituindo, assim, um protocolo de leitura na abertura de cada capítulo (CHARTIER, 1990). Abaixo segue um exemplo de ilustração.

Figura 3 - Ilustração que inicia o capítulo 2.

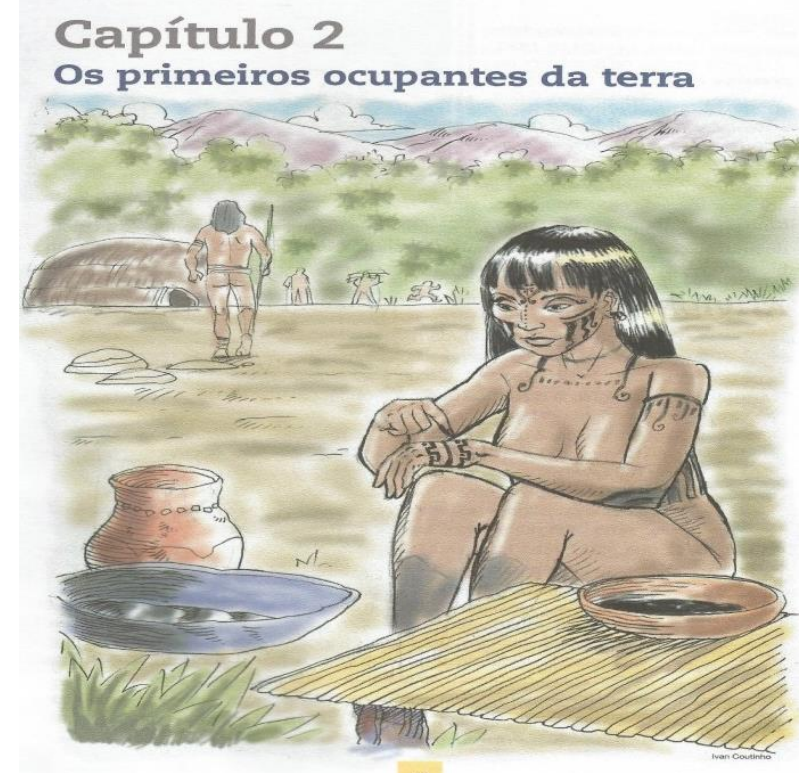

Fonte: Livro História do Mato Grosso do Sul (2005).

Além de uma referência do indígena idílico, o desenho faz uma alusão ao passado anterior à colonização, demonstrando um indígena que precedeu os contatos com o mundo europeu. O desenho transmite uma percepção estereotipada, que é muito distante da representação do indígena atual.

\section{Conteúdo}

O conteúdo é apresentado de forma descritiva e linear em relação aos fatos históricos, com início na pré-história até chegar ao Mato Grosso do Sul, conforme demonstra a linha do tempo no início do capítulo 2. 
Figura 4 - Linha do tempo apresentada no capítulo 2.

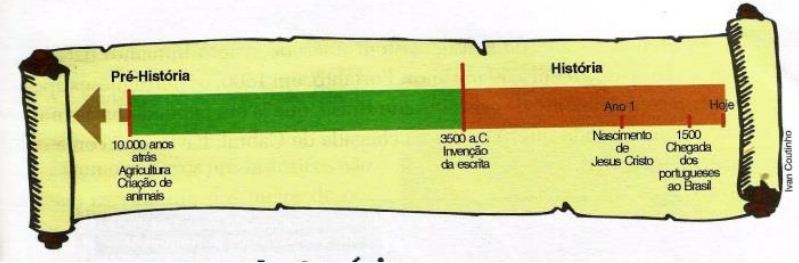

Fonte: Livro História do Mato Grosso do Sul (2005).

Quanto à questão territorial, as autoras lançam mão de um mapa sobre o tratado de Tordesilhas de 1494 (cap. 3, p. 28), com contornos do território atual do Brasil.

Figura 5 - Linha do tempo apresentada no capítulo

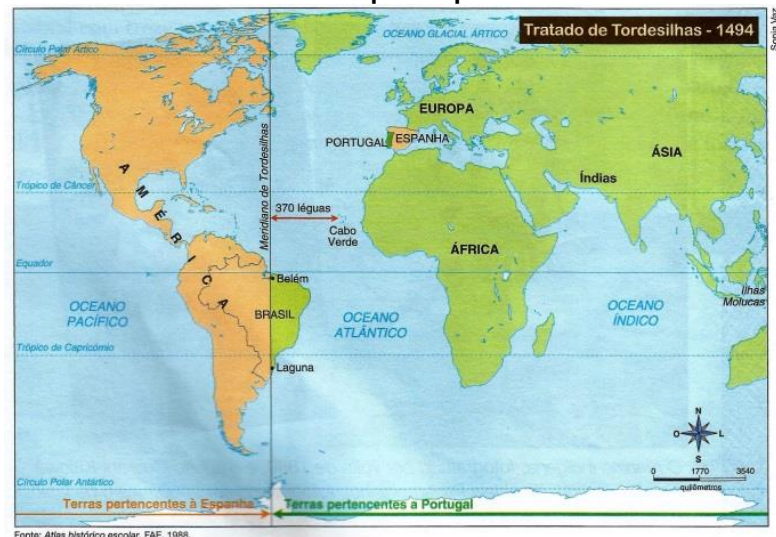

Fonte: Livro História do Mato Grosso do Sul (2005).

Entendemos que este erro histórico-geográfico condiciona concepções de identidade e representações territoriais equivocadas porque demonstra uma marcação nacional inexistente nesse período histórico.

O livro apresenta uma linguagem parcialmente adequada para o $5^{\circ}$ ano, isto porque no decorrer do texto são apresentados conceitos historiográficos complexos, o que torna a intervenção do docente imprescindível para o desenvolvimento do conteúdo.

Conforme mencionado, foi entrevistada uma professora da rede pública de ensino em Naviraí, interior de Mato Grosso do Sul que utilizou o livro na disciplina de História em 2017 em uma turma do 5. ano. Sobre o 
aspecto da linguagem a professora afirma que "[...] o texto é bom só que quase em todo o momento o professor tem que interferir porque existem palavras difíceis de compreensão e também existem conceitos históricos difíceis de compreender" (Professora entrevistada, ago. 2017).

A professora considerou ainda que essa linguagem é necessária: "[...] essa linguagem precisa existir para fortalecer a capacidade de compreensão dos alunos [...] é difícil, mas ela é necessária [...]". (Professora entrevistada, ago. 2017).

Para Chartier (1990) a recepção do texto, muitas vezes, tem a ver, em primeiro lugar, com a faixa etária dos leitores, pois "[...] não manipulam do mesmo modo a matéria escrita, uns por não saberem lê-la e outros por não quererem ou não poderem fazer". (CHARTIER, 1990, p. 122).

Rojas (1980), detecta três modos de se compreender a leitura:

1. A que não presta atenção na história no seu todo, mas somente a alguns episódios desligados uns dos outros. Esse modo de compreender a leitura reduz o texto a um só caminho. 2. Uma leitura que retém as fórmulas facilmente memorizáveis, como frases e refrões que forneçam lugares comuns e expressões feitas. Neste tipo de leitura não há relação íntima ou individualizada entre o leitor e a leitura. 3. Uma leitura que capta o texto na sua totalidade complexa sem reduzir aos episódios da sua intriga (ROJAS, 1980, apud CHARTIER, 1990, p. 123)

A tensão central na história da leitura ocorre por uma diferença na perspectiva de leitura. Uma perspectiva a vê como prática criadora, atividade produtora de sentidos singulares não reduzidas à intenção dos autores, e a outra, entende que o leitor é alguém que deve ter a leitura dirigida para chegar ao sentido pretendido, ou seja, deve passar por uma leitura autorizada. Essa autorização é concedida por sujeitos e/ou instituições imbricados no processo de produção e circulação do livro, tais como o autor, o comentador ou mediador de leitura, o editor, ilustrador, entre outros.

Em vários momentos do texto as autoras expõem fontes históricas (em sua maioria imagéticas) usadas apenas com ilustração e sem problematização e em muitos momentos, deslocada da discussão textual. 
Esses aspectos que podem ser observados abaixo na descrição da etnia Guarani e na escolha da imagem que não apresenta relação com o texto.

Há pelo menos 5 mil anos que a aprendizagem do cultivo de plantas, a domesticação de animais e as condições de solo e clima favorecem o desenvolvimento de diversos grupos étnicos que ocupam o território atual de Mato Grosso do Sul. Entre os nativos do território sul-mato-grossense, os mais numerosos, no século XVI, eram os Guarani. Excelentes agricultores plantavam principalmente o milho e a mandioca, base de sua alimentação.

Eles conheciam também o cultivo e a tecelagem do algodão, para a confecção de redes e vestimentas. Produziam potes de cerâmica para o armazenamento de alimento e os utilizavam, inclusive, para o sepultamento de seus mortos. Atualmente os Guarani são representados pelos Kaiowá e pelo Ñandeva.

A partir do século XVII, os colonizadores portugueses e espanhóis intensificaram seus ataques as aldeias dos Guarani. Eles exploravam a mão de obra indígena tanto no trabalho agrícola como na mineração. (GRESSLER; VASCONCELOS; SOUZA, 2005, p. 16).

Abaixo dessa explicação tem-se a seguinte imagem:

Figura 6 - Conteúdo e fonte imagética do capítulo 2

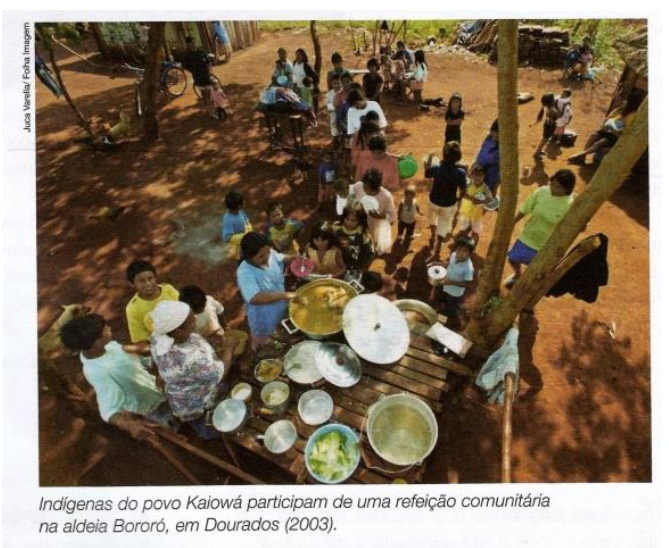

Fonte: Livro História do Mato Grosso do Sul (2005).

Conforme descrito no exemplo acima, as autoras narram as características da etnia Guarani Kaiowá e de forma deslocada destaca uma imagem atual, de 2003, de indígenas dessa etnia na aldeia Bororo, em uma refeição comunitária na região de Dourados (MS). Fontes imagéticas deslocados da temporalidade textual indicada aparecem com frequência no 
livro. Esses deslocamentos ou incoerências ocorrem muitas vezes porque o "impresso" é feito por muitas mãos.

Ao falar de "texto", Chartier (1990) está considerando as ideias, o conteúdo e o sentido, ao falar de "impresso", referese ao suporte no qual aquele conteúdo foi transferido. Portanto, o texto é feito pelo autor, já o impresso é feito por "[...] escribas e outros artesãos, por mecânicos e outros engenheiros, e por impressoras e outras máquinas". (CHARTIER, 1990, p. 126) Esta distância, que constitui o espaço no qual se constrói o sentido, foi muitas vezes, esquecida pelas abordagens clássicas que pensam a obra em si mesma, como um texto puro cujas formas tipográficas não tem importância, e também pela teoria da recepção que postula uma relação direta, imediata, entre o "texto" e o leitor, entre os "sinais textuais" manejados pelo autor e o "horizonte de expectativa" daqueles a quem se dirige. (CHARTIER, 1990, p. 127).

O impresso modifica-se, ainda, quanto ao papel, à tinta, as cores, as letras, os tamanhos, os formatos, tudo em função da queda nos preços, ou seja, mudanças materiais para fins comerciais. Também observamos que em todos capítulos são apresentados um suporte de leitura para os discentes intitulado "Fique sabendo" o qual aparece como um complemento relacionado ao conteúdo, constam: fontes escritas, imagéticas, fragmentos de livros e cultura material e imaterial sobre o estado do Mato Grosso do Sul. Os temas do "Fique sabendo" são variados tais como: mitologia, origem dos municípios, escravidão, violência contra os indígenas e negros, Guerra contra o Paraguai, léxicos indígenas incorporados em nosso vocabulário, conceitos históricos, comidas típicas e hábitos dos sujeitos sul mato-grossenses, como, por exemplo, tomar tereré ${ }^{5}$.

Essas informações trazidas nos textos ficam como curiosidades para a leitura dos discentes sem problematização e/ou sugestão de atividade. Abaixo segue um exemplo do box "Fique sabendo".

\footnotetext{
${ }^{5}$ Bebida feita de mate que se distingue do chimarrão por ser bebida com água fria e não água quente. Em sua produção, a erva mate utilizada no preparo do tereré difere do chimarrão por ter de ficar em repouso por volta de oito meses, em local seco, e de sofrer uma trituração grossa depois disso. Disponível em: < https://www.agron.com.br/publicacoes/mundo-agron/cultura-evariedades/2014/05/12/039376/historia-do-terere.html >. Acesso em: 29 set. 2018.
} 
Figura 7 - Box "Fique sabendo" do capítulo 2

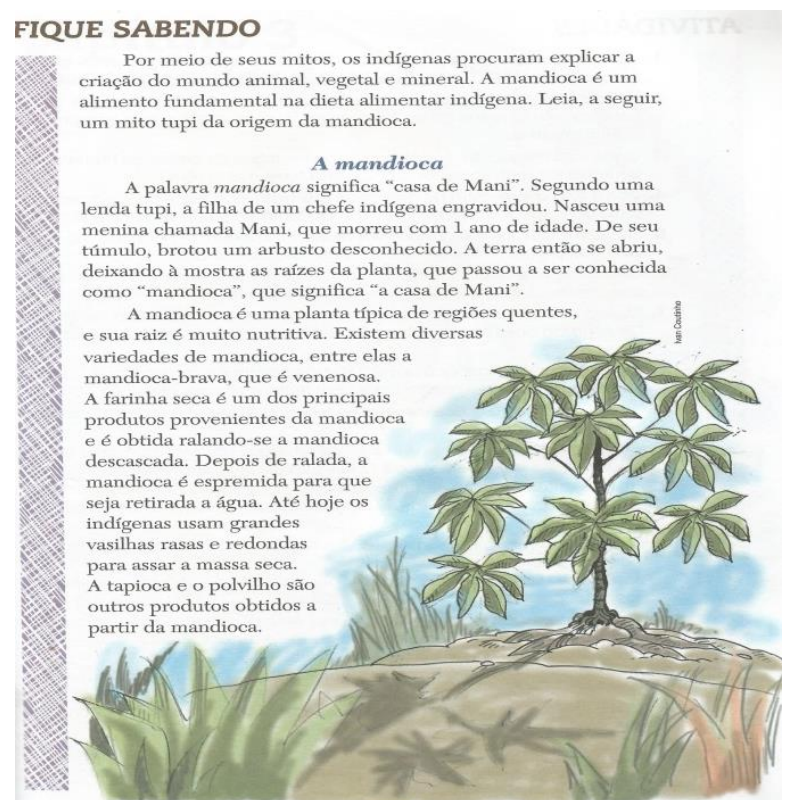

\section{Fonte: Livro História do Mato Grosso do Sul (2005).}

Os capítulos são finalizados com uma sequência de atividades que majoritariamente constituem-se de perguntas e respostas em que os discentes precisam retomar o texto para encontrar as respostas. Em raros momentos as atividades oferecem estratégias diferenciadas como facilitadoras da aprendizagem dos conteúdos. Essas atividades esparsas sugerem pesquisas, entrevistas, comparação de respostas entre os alunos, construção de história em quadrinhos, desenhos, estudo de mapas, debate, teatro e desfile.

Figura 8 - Atividades do capítulo 2 


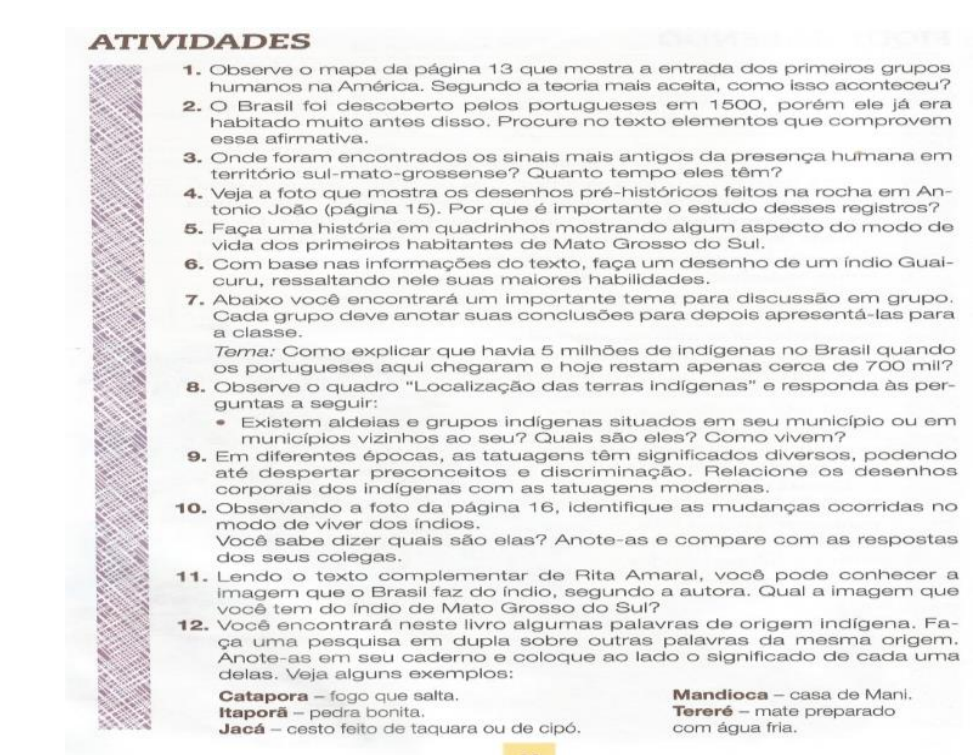

Fonte: Livro História do Mato Grosso do Sul (2005).

Sobre as atividades, Bittencort (2009), explica que o livro didático

[...] [a]lém de explicar os conteúdos escolares, é um suporte de métodos pedagógicos, ao conter exercícios, atividades, sugestões de trabalhos individuais ou em grupo e de formas de avaliação do conteúdo escolar. Essa sua característica de associar conteúdos e métodos de ensino explica a sua importância na constituição da disciplina ou do saber escolar. (BITTENCORT, 2009, p. 302, grifos da autora).

De acordo com a autora, os "métodos de ensino" e os "saberes escolares" são consolidados principalmente pela forma como as atividades são cobradas dos discentes, nesse caso, em sua maioria, como cópia do texto. Como única fonte primária para o professor e os alunos esse livro instaura uma forte representação sobre a cultura sul-mato-grossense na formação dos discentes. Pensando sobre esse conceito e a partir de alguns dicionários, Chartier (2011) apresenta algumas definições de representação: Para o Dicionario Furetière em 1960 significa "[...] imagem que remete a ideia e a memória dos objetos ausentes, e que nos apresenta tais como são". No sentido jurídico significa "[...] ocupar o lugar de alguém, ter em mãos sua autoridade". (CHARTIER, 2011, p 17).

O dicionário Frances do século XVII apresenta "[...] representação, como exibição de algo", está no sentido de comparecer pessoalmente e exibir as coisas. No quinto tomo do Dicionário de Autoridades publicado em 
1737, aparece o sentido de representar como "[...] fazer presente alguma coisa"; "exteriorizar alguma coisa, que existe, ou que você imagina" (CHARTIER, 2011, p. 18).

Os modelos operacionais que exploram o funcionamento da representação moderna entendem a representação de duas maneiras: "toda representação representa algo - dimensão transitiva ou transparente do enunciado; toda representação se apresenta representando algo dimensão reflexiva". (CHARTIER, 2011, p. 18-19, grifos do autor).

Esse livro didático destaca algumas questões sociais, políticas, culturais e econômicas do Mato Grosso do Sul. Devido a essa estrutura textual dificilmente os discentes conseguirão analisar a história desse estado na visão Chartiana de representação enquanto reflexão, pois reforça uma dimensão transitiva e transparente de uma história que na verdade, apresenta-se difusa e multiforme. Há muitos silêncios neste texto em relação aos habitantes do pantanal, das fronteiras, do centro do estado e das demais etnias ${ }^{6}$ existentes.

Portanto, a representação parte de representações individuais e coletivas, mas partem do real e do concreto, de algo que existiu e foi vivenciado concretamente, e não do imaginário onde pode incorrer em falsificações. O conceito de representação no mundo social está muito ligado a força simbólica, aos signos de força, sinais e indícios que foram adotados pelo social como representantes de práticas anteriores. (CHARTIER, 2011).

Martins (2011, p. 56), aponta estratégias necessárias ao professor que ensina história, das quais destacamos o item "d) consciência de que a experiência, pessoal e coletiva, da relação combinada professor-estudante com o presente e com o respectivo passado passa a fazer parte da narrativa histórica."

\footnotetext{
${ }^{6}$ No estado do Mato Grosso do Sul existem nove grupos étnicos: Kaiowá, Guarani, Terena, Kadiweu, Ofaié, Guató, Kinikinau, Atikum, Kamba, Chiquitano. Para maiores informações consultar: CHAMORRO, Graciela; COMBĖS, Isabelle. Povos indígenas em Mato Grosso do Sul: história, cultura e transformações sociais. Dourados, MS: Ed. UFGD, 2015.
} 
$\mathrm{Na}$ entrevista realizada com a professora notou-se que o livro é utilizado como única fonte disponível nas escolas para o ensino de história do Mato Grosso do Sul. Diante disso, os suportes oferecidos pelo livro dificultam os aspectos destacados no item d. por Martins (2011). Pois o texto tem um tom mais informativo do que formativo em relação à história do Mato Grosso do Sul. A partir dos apontamentos trazidos por Martins (2011), perguntamos: será que o estudante entende o seu "lugar social" e também e a "construção de suas experiências históricas"? ou seja, o aluno sul-mato-grossense se sente sujeito desse estado? De acordo com o autor, o ensino de história tem em sua

[...] missão mais destacada no estabelecimento da correlação substantiva entre a vida cotidiana do presente e o passado historicizado. O ensino de história deve tomar seu ponto de partida justamente nas questões que os estudantes percebem, em suas experiências atuais, não poderem ser adequadamente entendidas senão se recorrer uma volta ao passado. Seu "lugar social" é também o lugar em que se constroem suas experiências históricas. O encontro do lugar atual e do lugar do passado na experiência dos estudantes (e do público em geral, é bom lembrar) tem por objetivo ensejar a sensação de que o tema "diz respeito a mim [a nós]. (MARTINS, 2011, p. 56).

O desafio do professor diante desse material é fazer com o aluno perceba que não se trata de "algo do passado", mas em que medida essas "informações" se relacionam com a identidade dele e o modo de compreender a sua vida no presente, propiciando assim, uma reflexão histórica nos estudantes.

\section{Considerações Finais}

A escolha e a utilização do livro didático na escola é uma questão bastante complexa, uma vez que exige a definição de critérios que instrumentalizem o processo de escolha e fomentem a discussão sobre o ensino e a aprendizagem. Essa escolha constitui uma responsabilidade de natureza social e política e que muitas vezes traz dificuldades e incertezas aos professores. Nesse caso, a pesquisa identificou que o professor não tem 
escolha, pois trata-se do único livro didático disponível sobre a história regional do Mato Grosso do Sul.

Também percebemos que o livro didático é tido como um padrão curricular desejável, mesmo quando se considera a possibilidade de que ele seja modificado de alguma forma. Portanto, ele continua sendo um instrumento pedagógico indispensável no processo de construção do conhecimento, sendo um produto cultural, veiculado de valores ideológicos e culturais, além de seu conteúdo pedagógico específico de cada disciplina. Nesse sentido, o livro didático continua sendo um dos materiais mais utilizado nas escolas.

Observou-se que o livro aqui analisado propõe uma perspectiva de ensino em história linear, contém 15 capítulos dos quais 12 apresentam uma discussão mais detida sobre a história regional, enquanto os demais se inserem no contexto da história do Brasil. Por meio desta análise compreendemos alguns aspectos relevantes sobre o ensino da história como também a ausência de outros livros didáticos que se propõem a abordar a história regional do Mato Grosso do Sul.

As autoras fizeram um trabalho de pesquisa satisfatório, principalmente em relação a algumas atividades que problematizam a história regional, além disso, destacamos como aspectos positivos as fontes imagéticas e os mapas apresentados. No entanto, o ensino de história se faz por meio das fontes e o livro apresenta em sua maioria ilustrações. Portanto, é um texto bom, adequado, mas com muitos silenciamentos.

O ensino de história na perspectiva de Martins (2011, p. 52) deve capacitar o aluno a entender "[...] o papel estético da história na comunicação social em geral e seu efeito formador e conformador da consciência histórica das pessoas e em suas comunidades". Sobre esse quesito, o livro não oferece uma problematização de fontes que conduzam os discentes a uma reflexão de seu papel histórico na sociedade em que vivem.

O Historiador Carlos Vesentini, no artigo "Escola e livro didático de História", chama a atenção para os processos de "[...] criação e 
cristalização de uma memória" (BITTENCORT, 2009, p. 304), criadas pelo livro didático, como, por exemplo, manter o estereótipo de alguns grupos étnicos, causando uma generalização que é indevida para o ensino sobre esse tema.

Por isso, é necessário a consolidação de diálogo entre a História Escolar e a Acadêmica para evitar a manutenção de fatos históricos consagrados no ensino e, muitas vezes, baseados em bibliografia desatualizada. Por outro lado, encontramos muitos livros excelentes do ponto de vista da concepção de linguagem, do aspecto teórico e editorial, mas que não passam de mercadoria porque não "servem" para à turma a qual foi destinada. Isso acontece geralmente pelo distanciamento do pesquisador acadêmico com a educação básica.

Podemos dizer que existe uma produção significativa de história regional produzida nas Universidades que se fazem presentes no estado do Mato Grosso do Sul (UFMS, UFGD, UCDB), mas isso não tem se refletido nas escolas, ao ponto de termos apenas uma única produção de livro didático para $05^{\circ}$ ano. Pelo fato de haver apenas um, ele torna-se referência para o Ensino Fundamental II e o Ensino Médio, conforme ilustra a fala da professora entrevistada: "[...] eu sei que meus colegas da história usam ele nos outros anos"'. (Professora entrevistada, ago. 2017).

Mediante a isso, fazermos a seguinte indagação: qual o futuro do passado da história regional do Mato Grosso do Sul na educação básica?

\section{Referências}

BITTENCORT, Circe Maria Fernandes. Ensino de história: fundamentos e métodos. 3. ed. São Paulo: Cortez, 2009.

BOTO, Carlota. Novas histórias e seus velhos dilemas. Revista USP, São Paulo, n. 23, p. 22-33, 1994.

CHARTIER, Roger. Textos, impressos, leituras. In: CHARTIER, Roger. $A$ história Cultural: entre práticas e representações. Tradução de Maria

\footnotetext{
7 De acordo com o currículo do estado de Mato Grosso do Sul, a história regional deve ser abordada durante todo $05^{\circ}$. ano do Ensino Fundamental, depois, esse conteúdo é retomado no $7^{\circ}$. ano (dois tópicos no $4^{\circ}$. bimestre), no $8^{\circ}$. ano (dois tópicos no $3^{\circ}$. e $4^{\circ}$. bimestres), no $9^{\circ}$. ano (um tópico no $3^{\circ}$. bimestre), no $2^{\circ}$. e $3^{\circ}$ ano do Ensino Médio (um tópico no $3^{\circ}$. e $4^{\circ}$. bimestres).
} 
Manuela Galhardo. Rio de Janeiro: Ed. DIFEL, 1990. p.121-140. (Coleção Memória e Sociedade).

CHARTIER, Roger. Defesa e ilustração da noção de representação.

Fronteiras, Dourados, MS, v. 13, n. 24, p.1 5-29, jul./dez. 2011.

GRESSLER, Lori Alice; VASCONCELOS, Luiza Mello; SOUZA, Zélia Peres de. História do Mato Grosso do Sul: 4º série. São Paulo: FTD: 2005.

HÖFLING, Eloisa de Mattos. Notas para discussão quanto à implementação de programas de governo: em foco o Programa Nacional do Livro Didático. Educação \& Sociedade, ano 21, n. 70, p. 159-170, abr./2000.

LE GOFF, Jacques. História e memória. Tradução de Bernardo Leitão. 5. ed. Campinas, SP: Editora UNICAMP, 2003.

MARTINS, Estevão C. de Rezende. História: consciência, pensamento, cultura, ensino. Educar em Revista, Curitiba, n. 42, p. 43-58, out./dez. 2011.

MORTATTI, Maria do Rosário Longo. Notas sobre linguagem, texto e pesquisa histórica em educação. História da educação, Pelotas, v. 6, p. 6977, out. 1999.

MORTATTI, Maria do Rosário Longo. Os sentidos da alfabetização (São Paulo - 1876/1994). São Paulo: Ed. UNESP; Brasília: MEC/INEP/COMPED, 2000.

MUNAKATA, Kazumi. O livro didático como mercadoria. Pro-posições, Campinas-SP, v. 23, n. 3 (69), p. 51-66, set./dez.. 2012.

PROFESSORA entrevistada. Entrevista I. [ago. 2017]. [Entrevista cedida a] Dennis Rodrigo Damasceno Fernandes. Naviraí, 2017. 1 arquivo .mp3 (15 min.).

VALDEZ, Diane; AMARAL, Miriam Bianca do. História de Mato Grosso do Sul, 40. ou 50. ano. Curitiba, PR: Base Editora, 2011.

Recebido em 30 de setembro de 2018 Aprovado em 21 de dezembro de 2018 